Research Article

\title{
Finite Element Analysis of the Effect of Dental Implants on Jaw Bone under Mechanical and Thermal Loading Conditions
}

\author{
Dorsa Darvish $(\mathbb{D}$, Siamak Khorramymehr (D), and Mohammad Nikkhoo \\ Department of Biomedical Engineering, Science and Research Branch, Islamic Azad University, Tehran, Iran \\ Correspondence should be addressed to Siamak Khorramymehr; s.khorramymehr@srbiau.ac.ir
}

Received 13 July 2021; Accepted 10 September 2021; Published 4 October 2021

Academic Editor: Mohammad Yazdi

Copyright (C) 2021 Dorsa Darvish et al. This is an open access article distributed under the Creative Commons Attribution License, which permits unrestricted use, distribution, and reproduction in any medium, provided the original work is properly cited.

\begin{abstract}
Dental implants have been studied over the years to replace missing teeth. One of the conditions for the success of implants is their stability and resistance under the applied forces and minimal tension in the surrounding bone. The purpose of this dissertation is numerical and three-dimensional analysis of jaws with implants under mechanical and thermal loading by the finite element method. For this purpose, implant simulations (including ceramic crown, titanium root, and jaw bone) under dynamic and thermal load have been performed in Abacus software. In this simulation, it is considered that the jawbone is composed of two areas, one area is the superficial bone tissue (cortical) and the other part is the spongy tissue. Implants are usually made of different metals or ceramics with a bone-like structure that are compatible with body tissues. Implants are currently made of titanium metal. Therefore, titanium metal has been used for modeling implants in this dissertation. The implant crown is also considered as a ceramic material. In the simulation, the effect of stresses imposed by the implant on the jawbone is performed. In this simulation, mechanical force is applied to the upper part of the implant and force enters the jawbone through the implant, which causes tension at the junction of the implant to the jawbone. To investigate the effect of thermal loads, different temperature conditions are considered by considering the decrease in temperature and increase in temperature on the tooth surface and its effect on the implant and the jaw bone. After validation and ensuring the accuracy of the modeling, it has been observed that, with increasing mechanical load, the stresses created in all parts of the ceramic coating, titanium implants, and jawbone have increased. It is also observed that the stress created in the titanium implant due to the application of negative heat flux was about twice as much as the stress created due to the application of positive heat flux.
\end{abstract}

\section{Introduction}

Given the importance of the human body and the importance and impact of the type and properties of implants in the jaw, as well as its impact on human body function, choosing the best parameters both in terms of mechanical properties and biocompatibility (compatibility with the human body) is essential. Also, the function of dental implants and its effect on the jaw bone is affected by mechanical and thermal loads, which is also important and necessary to study this issue.

Therefore, by modeling and analyzing the effect of dental implants on the jaw bone in terms of mechanical and thermal loading, as well as considering different properties for the implant, it is possible to have a detailed study on its performance, which is very important $[1-3]$.
We may lose one or more of our teeth for a variety of reasons. Not having one or more teeth can cause problems such as loss of beauty. There are several alternatives to missing teeth, among which dental implants are the best choice. However, various reasons, such as the inability to withstand the forces and torques and the intolerance of high temperatures, can lead to failure in the implantation process. A dental implant is a titanium screw that replaces a missing tooth by being inserted into the jawbone. Dental implants can be one-piece or two-piece, with the crown and root joined by a screw. Dental implants are an alternative to shaven-tooth bridge prostheses, and the primary goal of introducing this therapy (dental implant) is to ensure that no teeth will be shaved or damaged in the future owing to the bridge base. 
Oguz et al. [4] studied the static, dynamic, and fatigue behavior of dental implants using the finite element method. In this study, a dynamic load is applied to the occlusal surface for 5 seconds and the fatigue life is calculated based on Goodman, Soderbergh, and Gerber criteria. They found that von Mises maximum stress in dynamic loading is greater than static loading. Kong et al. [5] investigated the effect of thread change in maximum stress on bone and implants through finite element analysis. The results showed that the thread pitch plays an important role in the strength of the implant under axial load. Djebbae et al. and Tian et al. [6, 7] obtained the stress distribution in dentures by the finite element method. The amount of stress, especially at the junction of the implant bone, was examined. They found that force and direction of loading have a large effect on the amount of stress. Huang et al. and Dorogoy et al. $[8,9]$ used 11 different finite element models to study the stress distribution and slip of implants. The contact of the surfaces is of frictional type. The results show that, in fastloading implants, especially in off-axis loads, the stress on the bone around the implant is very high. As the number of threads and the contact surface of the bone and implant increase, the stress distribution and slip of the implant and bone surface decrease. Guan et al. and Yazdi $[10,11]$ performed dynamic modeling and simulation of the dental implant placement process using the finite element method. In this study, by examining the effect of different placement depths on spongy bone and dense bone, it was found that increasing the placement depth increases the amount of stress in dense bone. The authors of [12-14] presented finite element analysis of thermal implants exposed to heat. In this study, by observing the results of thermal stresses, it can be seen that thermal stresses have small values, and it is also due to small temperature changes in the complex. The highest stress is related to the abutment, which is also caused by the stiffening torque. The authors in $[15,16]$ reviewed the mechanical design requirements of dental implants and found that compressive loading stabilizes the implant in the jawbone and tensile loading of the implant loosens and shear loading causes the implant to fail. Creating rough surfaces also improves the adhesion between the implant and the bone. Using the finite element method, the authors of $[17,18]$ studied the influence of the tooth and jaw bone-implant contact model on maximum implant stress. The largest stress can occur in the neck area of the implant and in the connection points with the dense bone under oblique loading, according to the stress distribution. The authors of $[19,20]$ used the finite element method to undertake static and dynamic analysis of dental implants that Abacus specialist software was used in this investigation. Modeling geometry, specifying material characteristics, boundary conditions, contact conditions, loading, and elementing for bone-implant simulation were all done in Abacus program. There will be two analyses, each with a distinct force. The ceramic cap is subjected to a force of 100 Newtons at a 45-degree angle during static analysis. All modeling phases are inserted into dynamic analysis with a force of 400 Newtons in 0.01 seconds, identical to static analysis. In static analysis, the highest von Mises stress was $82.5 \mathrm{MPa}$, but in dynamic analysis, it was $770.2 \mathrm{MPa}$. In contrast to dynamic analysis, the maximum stress in static analysis is lower. Dynamic analysis allows for a smaller maximum displacement than static analysis. The authors of $[21,22]$ used finite element simulation to evaluate the biomechanical behavior of mini-implants under real-world working settings. Stress analysis of two distinct quality of the D2 and D3 jawbone around three types of mini-implants was performed using the finite element method in this study due to the relevance of placing short implants in confined spaces between the edentulous region. Three varieties of Osteocare, Dio, and Dentis mini-implants were included in this experimental investigation. The highest component of the abutment was loaded with a vertical force of $100 \mathrm{~N}$ and a lateral force of $100 \mathrm{~N}$ at a 45-degree angle.

ABAQUS software was used to analyze stress levels in the mini-implant and surrounding bone. The findings revealed that the amount of von Mises stress in D3 bone for all implants is higher than D2 bone and that the level of stress in the cortical bone is higher than the spongy bone. Furthermore, all the systems studied had identical stress distributions in the cortical bone. Additionally, the initial implant thread caused the most stress in the implant's neck, but the Osteocare mini-implant created less tension in the bone. The topology optimization technique in dental implants was examined using Abacus software by [23-25]. This article discusses how to use Abacus software to optimize dental implant architecture. One of the types of optimization in Abacus software is topology optimization. Topological optimization is a mathematical method for determining the best material distribution shape for a structure in a given space. Optimization minimizes the weight of the material, resulting in lower assembly costs and time. The authors of [26-28] used the finite element approach to simulate the mechanical performance of dental implants comprised of memory materials. A sample of existing dental implants, as well as a portion of the jawbone, were modeled in Abacus software and statically assessed for this purpose. Finally, the implant's level of stress was compared to that of other implants made of standard materials. The results show that when the memory implant was utilized, the stress values in the implant were lower than when the nickel-titanium implant was used. The amount of stress transferred from the nitinol implant to the nickeltitanium implant to the jawbone was also fewer in the regions which were subjected to increased force and stress. The authors of $[29,30]$ used the finite element approach to investigate the effect of geometric and mechanical features on the stress distribution of the dental implant system. The findings demonstrate that the angle and step of fastening are critical in boosting implant stability and minimizing bone stress.

Over the years, dental implants have been researched as a way to replace missing teeth. One of the requirements for implant success is their stability and resistance to applied stresses, as well as minimum tension in the surrounding bone. The goal of this work is to use the finite element method to perform numerical and three-dimensional analysis of jaws with implants under mechanical and thermal loading. Implant simulation (containing ceramic crown, titanium root, and jaw bone) is performed in Abacus program under dynamic and thermal load for this purpose. The jawbone is divided into two sections in this simulation: the superficial bone tissue (cortical) and the spongy tissue. Implants are typically made of metals or ceramics that have a 
bone-like structure and are compatible with bodily tissues. Currently, titanium metal is used to make implants [31]. As a result, in this article, titanium metal is used to simulate the implant. A ceramic substance is also used to make the implant crown. The effect of implant-induced strains on the jawbone is simulated in this simulation. Mechanical force is given to the top section of the implant and force is applied to the jawbone through the implant in this simulation, resulting in strains and concentrations of stresses at the implant-jawbone junction. Different temperature settings are investigated to investigate the effect of thermal stresses, including temperature decreases and increases, on the tooth surface, as well as their effect on the implant and the jaw bone. High temperature tolerance can arise when drilling the jawbone or when drinking hot liquids, according to the findings of this study. As a result, the goal of this research is to use the finite element method to conduct a numerical and three-dimensional analysis of jaws with implants under mechanical and thermal loads. Thus, we derive the stress distribution, strain, and displacement in the implant and jawbone by modeling the set of implants and jawbone while considering mechanical and thermal loads, and we investigate the effect of various parameters on them.

\section{Research Method}

2.1. Modelling Software. The study approach involves modeling the geometric model of the jaw bone in Solidwork's software in two states: cortical and spongy. SolidWorks software is also used to construct the geometric model of the implant set and its cover, which is then inserted in the bone. The boundary and force properties and conditions are determined after importing the designed geometric models into the Abaqus analytical software, and the model is then evaluated and examined after meshing. Mechanical and thermal loads are applied to the model in this finite element study, and the heat load due to drinking hot and cold drinks is applied to the whole surface of the ceramic coating in the form of heat flux per unit area. The size of the element converges to improve the accuracy of the simulation findings. The outcomes of modeling this research are also compared to the results of valid articles for validation. The jaw and the implant are presumed to be in perfect contact in this study and that there is no slippage between them. In fact, the bone and the titanium implant are joined, to use medical terminology. The step is utilized directly or implicitly in the analysis, which is dynamic. The simulation approach is offered after the stages of modeling and specifying the required problem in this program are accomplished step by step in different modules of Abacus software.

2.2. Create a Geometric Model. The first stage in issue software modeling is to develop a geometric model of the problem's pieces. The geometry of the ceramic crown, titanium root, and jawbone, as depicted in Figures 1-3, is initially modeled for this purpose. These parts' modeling is three-dimensional and adaptable.

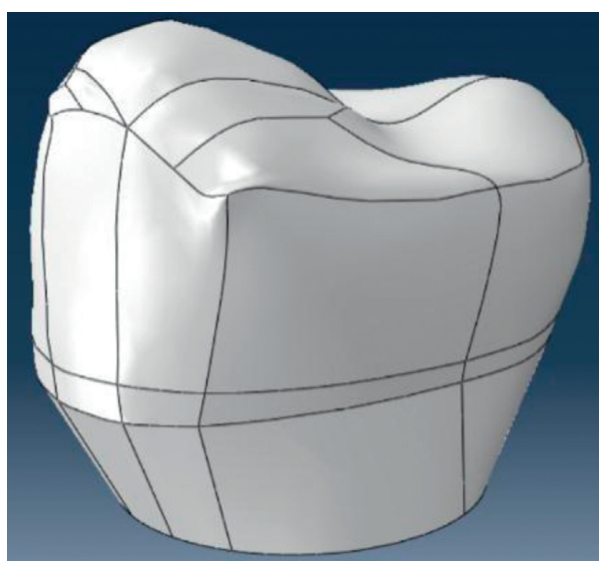

Figure 1: Geometric modeling of a ceramic crown.

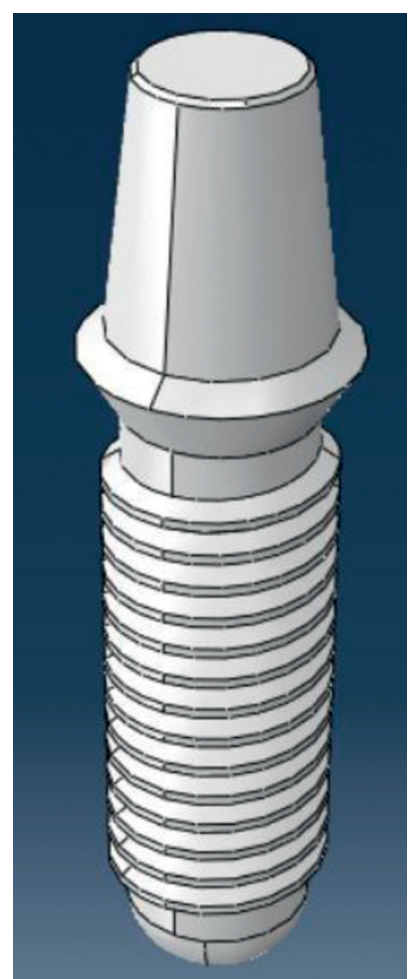

Figure 2: Geometric modeling of titanium root.

2.3. Definition of Material Properties. The crown of the implant is constructed of ceramic, while the root is composed of titanium Ti6Al4V metal, and the jawbone is divided into two groups: cortical and spongy. As a result, mechanical properties such as density, Young's modulus, Poisson's ratio, and plasticity qualities, as well as thermal properties such as specific heat, are determined for each of the materials mentioned. The Drucker-Prager plastic model is combined with the ductile damage model to create the ceramic material for the implant crown. The metal root of the implant is likewise subjected to Johnson Cook's damage model. The jawbone has also benefited from Johnson Cook's elastic and plastic characteristics. Table 1 shows the mechanical properties of implant components. 


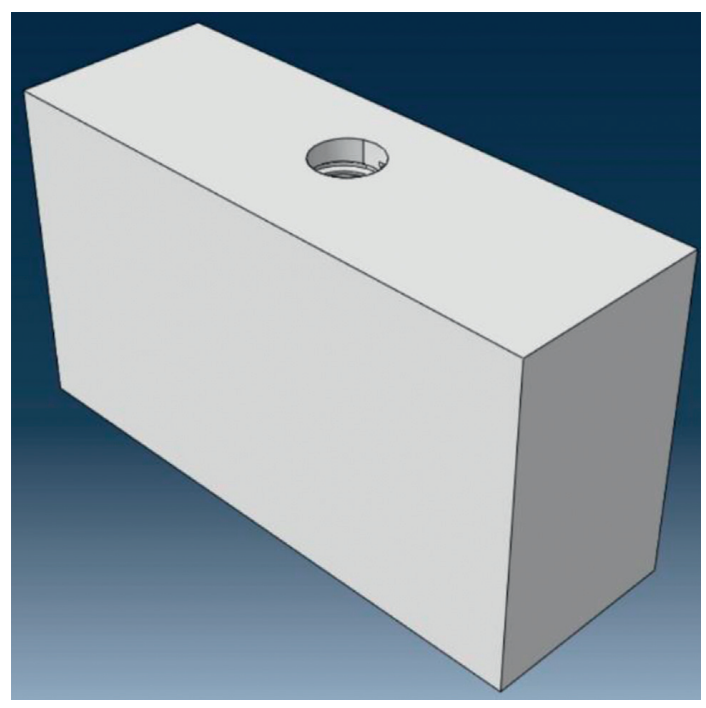

FIGURE 3: Geometric modeling of the jawbone.

TABle 1: Mechanical properties of implant components.

\begin{tabular}{|c|c|c|c|c|c|}
\hline Piece & Identity & Density $\left(\mathrm{kg} / \mathrm{m}^{3}\right)$ & Modulus of elasticity (GPa) & Poisson's ratio $(\Gamma)$ & Surrender strength (MPa) \\
\hline Ceramic coating & Porclain & 2450 & 70 & $0 / 19$ & 500 \\
\hline Implant & Ti6Al4V metal & 4500 & 110 & $0 / 35$ & 800 \\
\hline
\end{tabular}

Table 2 shows the mechanical properties of bone components.

Table 3 shows the thermal properties of the model components.

2.4. Assembly of Parts. Different pieces of the model, including as the ceramic crown, titanium root, and jawbone, are positioned adjacent to each other and their relative positions are defined for this reason. Figure 4 depicts the model parts being put together.

2.5. Define the Type of Analysis. The analysis is classified as linked temp-displacement. This problem clearly considers the type of solver. This solution examines the governing equation system using the element diagonal mass matrix and the law of explicit integration. Figure 5 depicts the software's definition of this type of analysis for massive transformations.

2.6. Define Boundary Conditions and Loadings. The jawbone's lateral surfaces are considered joint support in this article. The upper surface of the ceramic crown has also been subjected to two forms of loading: mechanical and thermal. The entire upper surface of the ceramic crown is paired with a reference point on the same surface in order to establish mechanical and thermal loading, and then, the intended loads are applied to this point. On the upper surface of the crown, a compressive force is exerted. Three distinct values for the amount of compressive force have been evaluated in various analyses to investigate the effect of the amount of force on the behavior of the dental implant. A heat flux is delivered to the upper surface of the ceramic crown to provide a thermal burden. Three distinct values for the amount of heat flow have been investigated in various analyses to investigate the effect of heat flux on the behavior of dental implants. As a result, Abacus software is used to define the above boundary conditions and loads. The articular support on the lateral sides of the jawbone is defined in Figure 6.

Figure 7 shows the application of mechanical load as a compressive force to the upper surface of the crown.

The application of heat flux is seen in Figure 8. It is worth noting that the starting temperature and surrounding environment are both 27 degrees Celsius.

2.7. Meshing. The mesh of the model parts in the form of hexagonal meshes with an element size of $0.2 \mathrm{~mm}$ is taken into account. Temperature-displacement coupling elements, explicit library, and quadratic geometric order are among the elements in its family, with a total of 1,986,000 elements. In Section 3, we will look into mesh independence for this amount of elements. The model set correlation is depicted in Figure 9.

\section{Analysis of Results}

3.1. Check the Independence of the Mesh. The simulation results for numerous different element sizes were explored to ensure that the results from the elements and meshes were independent. For varying sizes of model elements, Table 4 indicates the maximum output stress values in the ceramic coating. 
TABLE 2: Mechanical properties of bone components [28].

\begin{tabular}{|c|c|c|c|c|}
\hline $\mathrm{Gxy}=4850$ & $\begin{array}{l}\mathrm{Uxy}=0.3 \\
\mathrm{Uyx}=0.3\end{array}$ & $E x=12600$ & \multirow{3}{*}{$\rho=1700$} & \multirow{3}{*}{ Cortical bone } \\
\hline $\mathrm{Gyz}=5700$ & $\begin{array}{c}\mathrm{Uyz}=0.253 \\
\mathrm{Uzy}=0.39\end{array}$ & Ey $=12600$ & & \\
\hline $\mathrm{Gxz}=5700$ & $\begin{array}{c}\mathrm{Uxz}=0.253 \\
\mathrm{Uzx}=0.39\end{array}$ & $\mathrm{Ez}=19400$ & & \\
\hline$G x y=68$ & $\begin{array}{c}\mathrm{Uxy}=0.055 \\
\mathrm{Uyx}=0.01\end{array}$ & $E x=1148$ & \multirow{3}{*}{$\rho=270$} & \multirow{3}{*}{ Sponge bone } \\
\hline $\mathrm{Gyz}=68$ & $\begin{array}{c}\mathrm{Uyz}=0.01 \\
\mathrm{Uzy}=0.055\end{array}$ & $\mathrm{Ey}=270$ & & \\
\hline $\mathrm{Gxz}=434$ & $\begin{array}{l}U x z=0.322 \\
U z x=0.322\end{array}$ & $\mathrm{Ez}=1148$ & & \\
\hline
\end{tabular}

Table 3: Thermal properties of model components.

\begin{tabular}{lccc}
\hline Piece & Thermal expansion coefficient & Thermal conductivity coefficient & Specific heat \\
\hline Ceramic coating & $9 / 5$ & 5 & 920 \\
Implant & $8 / 6$ & $6 / 7$ & 523 \\
Sponge bone & $0 / 031$ & $0 / 3$ & 1440 \\
Cortical bone & $0 / 028$ & $0 / 58$ & 1300 \\
\hline
\end{tabular}

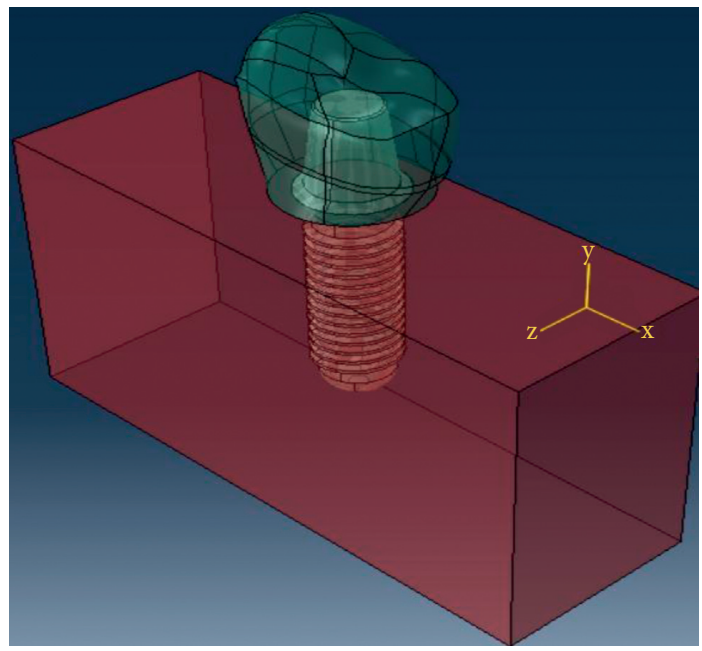

FIGURE 4: Assembly of model parts.

As can be observed, the results are nearly consistent from element sizes equal to $0.2 \mathrm{~mm}$ onwards, indicating that the analysis findings are reliable and that the solution has attained convergence with a high degree of accuracy. The findings are also shown to be independent of the number and size of elements and meshes when using this element size. As a result, various findings have been derived using this element's size.

3.2. Validation. A comparison was done between the results of the current work and the results connected to Niroumand and Jafari in order to validate and evaluate the accuracy of the modeling and numerical solution method. Table 5 shows the maximal von Mises stress of the current investigation and compares it to the results of robust and extensive research for this goal. These values are provided for the model's various components. The stresses in the table are measured in megapascals.

Because there is a small discrepancy between the results of this study and the results of Niroumand and Jafari's publication, it is concluded that the current modeling is accurate and legitimate.

3.3. Stress Results. For three distinct loads, Figure 10 depicts the stress distribution in the ceramic coating area $(2500 \mathrm{~N}$, $5000 \mathrm{~N}$, and7500). 


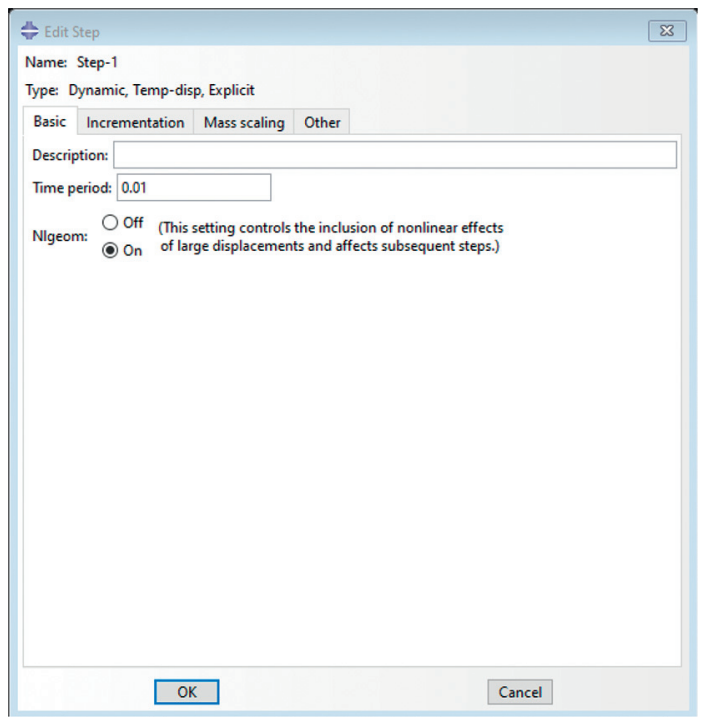

FIGURE 5: A displacement-temperature coupling with large deformations is defined as the kind of analysis.

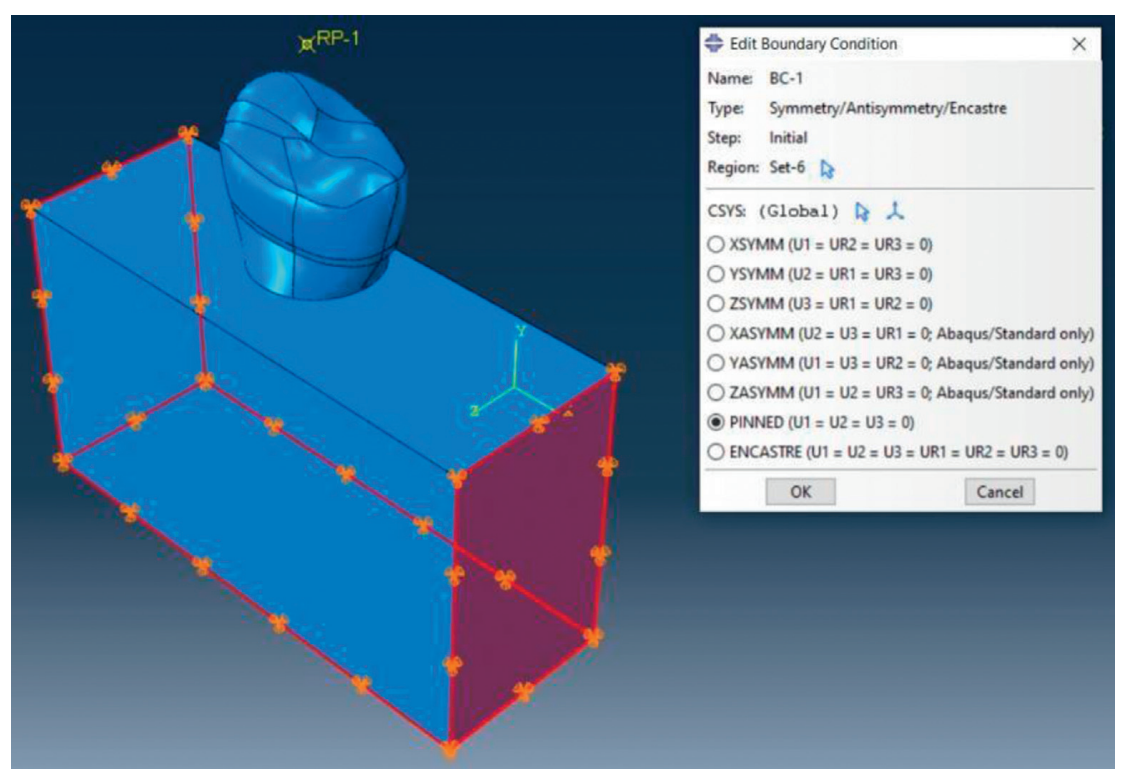

FIgURE 6: Definition of the articular support on the lateral surfaces of the jawbone.

The stress distribution in the titanium implant region for three distinct loads is shown in Figure $11(2500 \mathrm{~N}, 5000 \mathrm{~N}$, and $7500 \mathrm{~N}$ ).

Figure 12 depicts the distribution of stress in the bone under three different loads $(2500 \mathrm{~N}, 5000 \mathrm{~N}$, and $7500 \mathrm{~N})$.

3.4. Strain Results. Figure 13 shows the strain distribution in the ceramic coating section for three different loads $(2500 \mathrm{~N}$, $5000 \mathrm{~N}$, and 7500).

The strain distribution in the titanium implant part for three distinct loads is shown in Figure $14(2500 \mathrm{~N}, 5000 \mathrm{~N}$, and $7500 \mathrm{~N})$.
Figure 15 shows the strain distribution in the bone for three different loads $(2500 \mathrm{~N}, 5000 \mathrm{~N}$, and $7500 \mathrm{~N})$.

3.5. Deformation Results. Figure 16 shows the deformation distribution in the ceramic coating section for three different loads $(2500 \mathrm{~N}, 5000 \mathrm{~N}$, and 7500).

Figure 17 shows the deformation distribution in the titanium implant section for three different loads $(2500 \mathrm{~N}$, $5000 \mathrm{~N}$, and $7500 \mathrm{~N}$ ).

Figure 18 shows the distribution of deformation in the bone for three different loads $(2500 \mathrm{~N}, 5000 \mathrm{~N}$, and $7500 \mathrm{~N})$. 


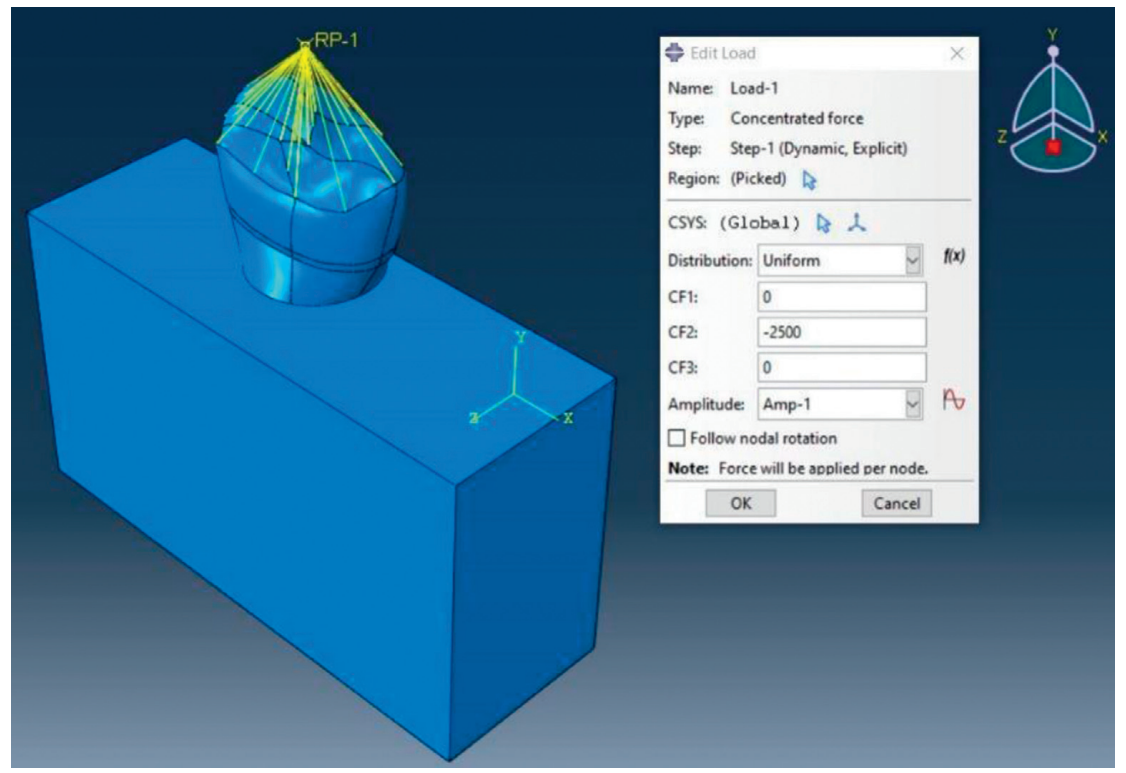

FIGURE 7: Definition of mechanical load as compressive force to the upper surface of the crown.

\begin{tabular}{l}
\hline Edit Load \\
Name: Load-2 \\
Type: Concentrated heat flux \\
Step: Step-1 (Dynamic, Temp-disp, Explicit) \\
Region: Set-8 \\
\hline Note: Heat flux will be applied per node. \\
Distribution: Uniform \\
Magnitude: 0.125 \\
Amplitude: $\quad$ (Instantaneous) \\
Degree of freedom: $11 *$ Cancel \\
\hline OK
\end{tabular}

Figure 8: Applying heat flux. 


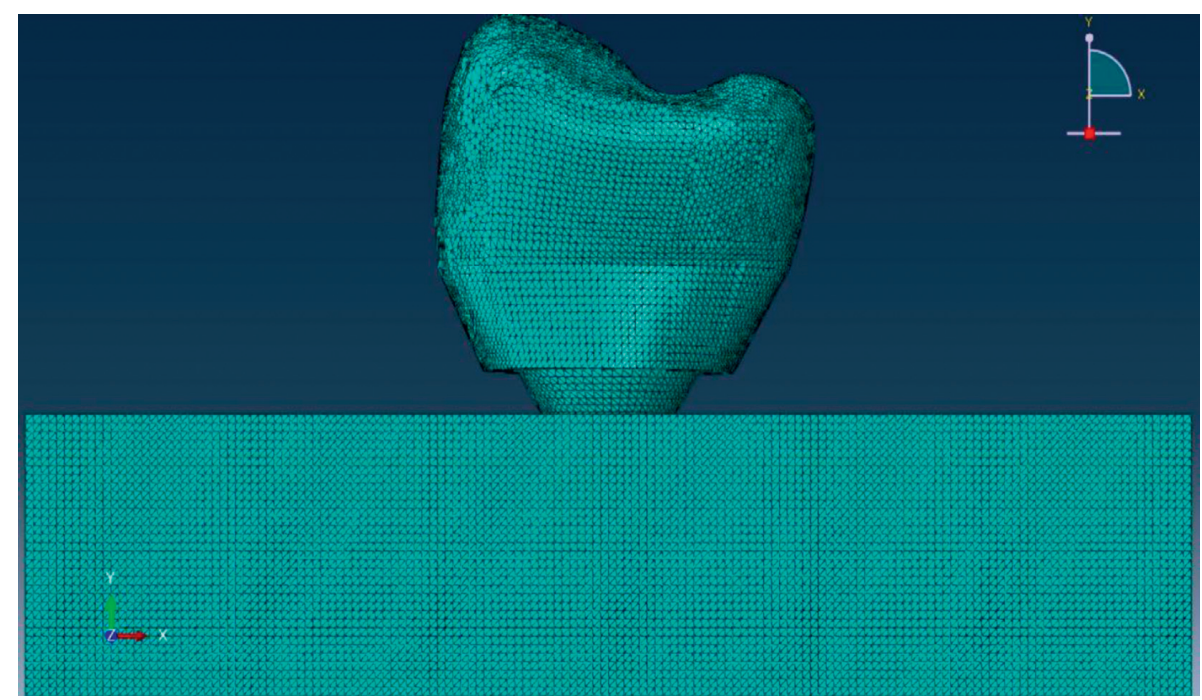

Figure 9: Modeling mesh set.

TABLE 4: Maximum output stress values in the ceramic coating section for different element sizes.

\begin{tabular}{lr}
\hline Element size $(\mathrm{mm})$ & Maximum output stress (MPa) \\
\hline 2 & 48.83 \\
1 & 48.29 \\
0.5 & 47.95 \\
0.2 & 47.76 \\
0.1 & 47.68 \\
0.05 & 47.65 \\
\hline
\end{tabular}

TABLE 5: Maximum output stress values for different element sizes.

\begin{tabular}{lccc}
\hline Different model components & Existence research & Niroumand and Jafari research & Percentage error \\
\hline Implant & 85.01 & 80.72 & 5.32 \\
Sponge bone & 2.33 & 2.22 & 4.86 \\
Cortical bone & 30.60 & 29.12 & 5.07 \\
\hline
\end{tabular}

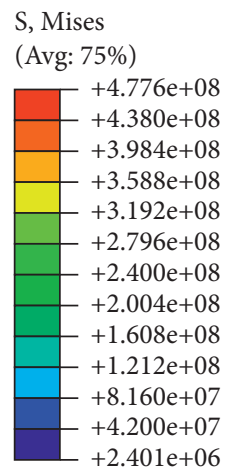

Max: $+4.776 \mathrm{e}+08$

Elem: IMPLANT-1-1.16494

Node: 542

Min: $+2.401 \mathrm{e}+06$

Elem: IMPLANT-1-1.11893

Node: 8228
S, Mises

(Avg: 75\%)
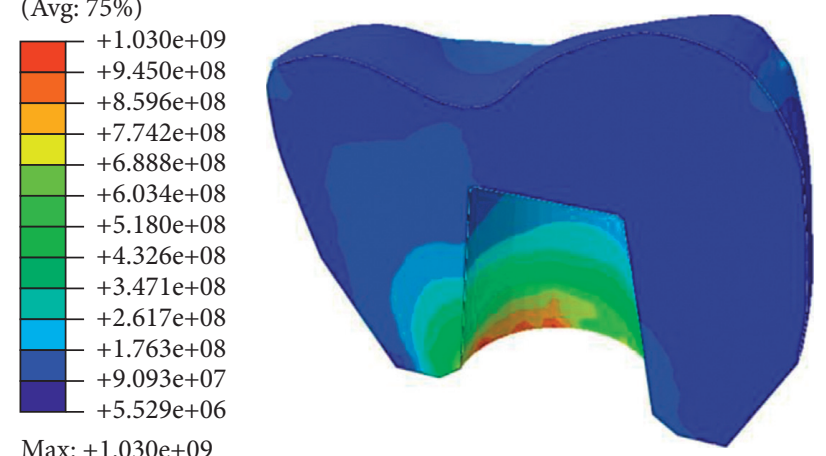

Max: $+1.030 \mathrm{e}+09$

Elem: IMPLANT-1-1.16494

Node: 542

Min: $+5.529 \mathrm{e}+06$

Elem: IMPLANT-1-1.11848

Node: 26

(a)

(b)

Figure 10: Continued. 


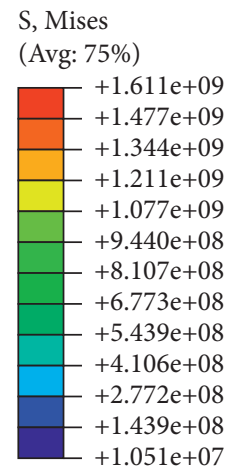

Max: $+1.611 \mathrm{e}+09$

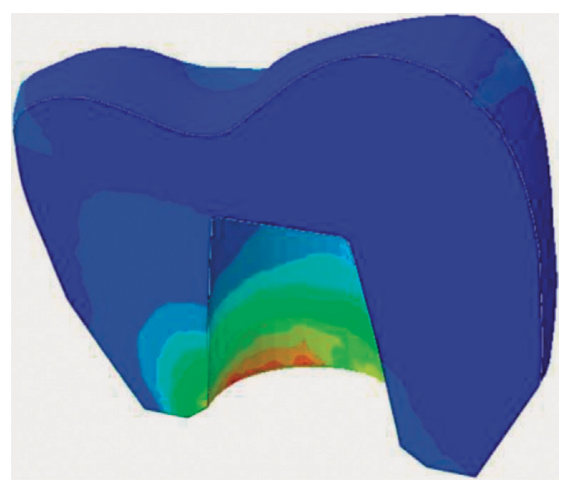

Elem: IMPLANT-1-1.16494

Node: 542

Min: $+1.051 \mathrm{e}+07$

Elem: IMPLANT-1-1.13455

Node: 8521

(c)

FIgURE 10: The stress distribution in the ceramic coating portion for loads of 2500,5000 , and $7500 \mathrm{~N}$.

S, Mises

(Avg: $75 \%$ )

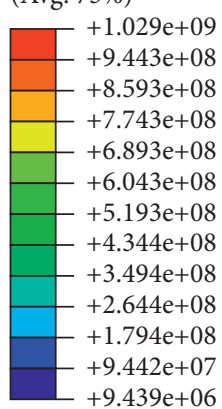

Max: $+1.029 \mathrm{e}+09$

Elem: IMPLANT-2-2.18480

Node: 2533

Min: $+9.439 \mathrm{e}+06$

Elem: IMPLANT-2-2.5124

Node: 1717

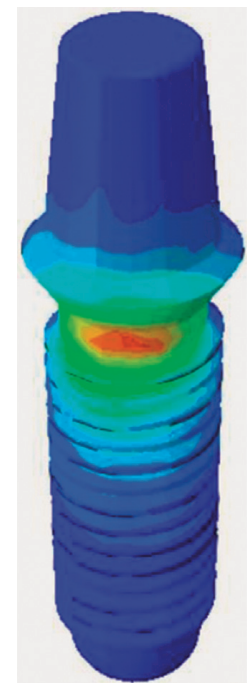

(a)
S, Mises

(Avg: 75\%)

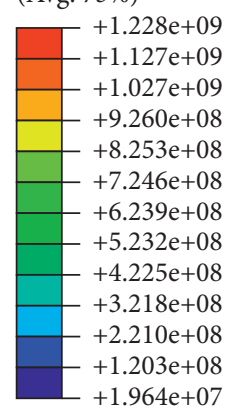

Max: $+1.228 \mathrm{e}+09$

Elem: IMPLANT-2-2.9656

Node: 2519

Min: $+1.964 \mathrm{e}+07$

Elem: IMPLANT-2-2.5124

Node: 1717

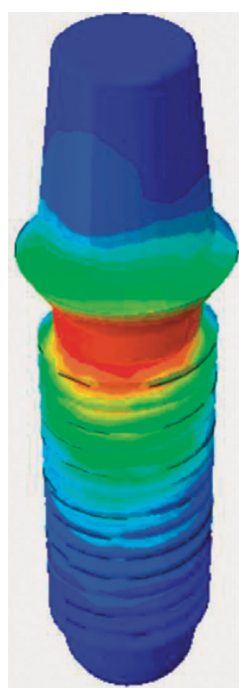

(b)

S, Mises

(Avg: 75\%)

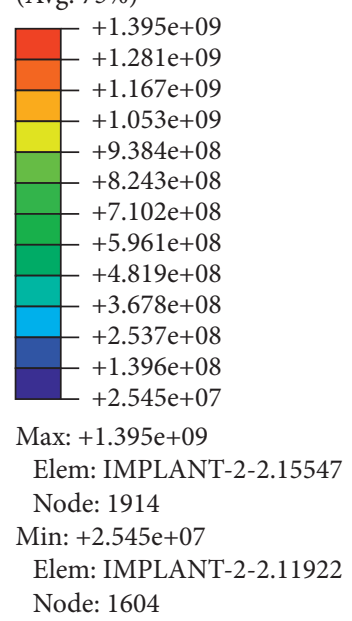

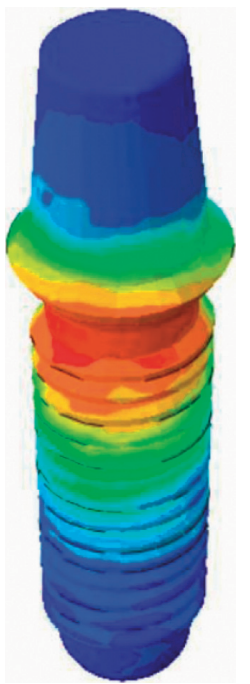

(c)

FIGURE 11: Stress distribution in the titanium implant section for loads: (a) 2500, (b) 5000, and (c) $7500 \mathrm{~N}$. 


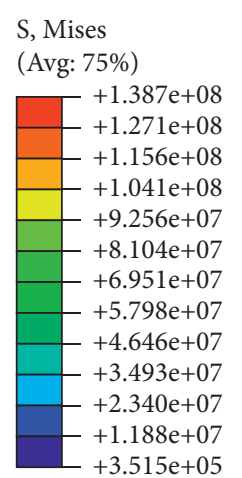

Max: $+1.387 \mathrm{e}+08$

Elem: MANDIBLE-1.2082

Node: 1984

Min: $+3.515 \mathrm{e}+05$

Elem: MANDIBLE-1.8510

Node: 6221

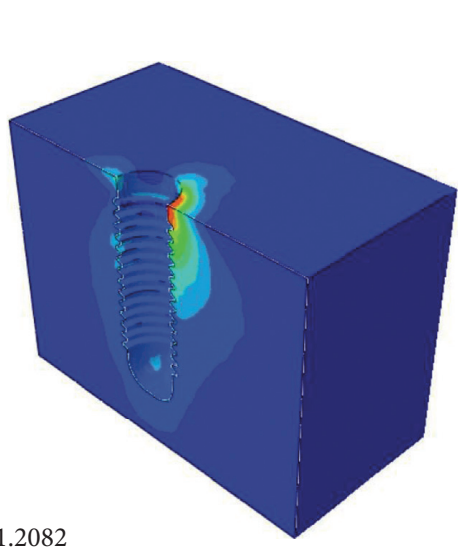

S, Mises

(Avg: 75\%)

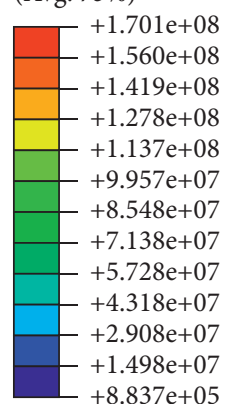

Max: $+1.701 \mathrm{e}+08$

Elem: MANDIBLE-1.31065

Node: 1983

Min: $+8.837 \mathrm{e}+05$

Elem: MANDIBLE-1.12751

Node: 6201

(a)

(b)

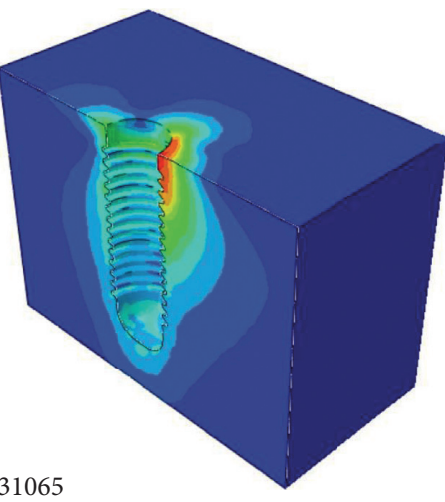

S, Mises
(Avg: $75 \%)$
\begin{tabular}{|r|r}
\hline & $+2.222 \mathrm{e}+08$ \\
\hline & $+2.038 \mathrm{e}+08$ \\
& $+1.853 \mathrm{e}+08$ \\
& $+1.669 \mathrm{e}+08$ \\
& $+1.485 \mathrm{e}+08$ \\
\hline & $+1.300 \mathrm{e}+08$ \\
\hline & $+1.116 \mathrm{e}+08$ \\
\hline & $+9.316 \mathrm{e}+07$ \\
& $+7.472 \mathrm{e}+07$ \\
\hline & $+5.628 \mathrm{e}+07$ \\
& $+3.784 \mathrm{e}+07$ \\
& $+1.940 \mathrm{e}+07$ \\
& $+9.632 \mathrm{e}+05$
\end{tabular}

Max: $+2.222 \mathrm{e}+08$

Elem: MANDIBLE- 1.31143

Node: 1981

Min: $+9.632 \mathrm{e}+05$

Elem: MANDIBLE-1.39538

Node: 2179

(c)

Figure 12: The distribution of stress in the bone segment for loads of 2500,5000 , and $7500 \mathrm{~N}$.

LE, Max. Principal (Avg: 75\%)

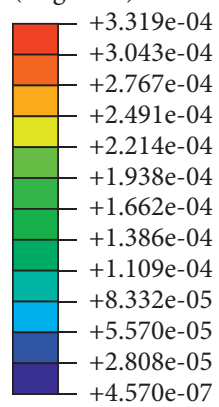

Max: $+3.319 \mathrm{e}+04$

Elem: IMPLANT-1-1.16494

Node: 542

Min: $+4.570 \mathrm{e}+07$

Elem: IMPLANT-1-1.563

Node: 3537
LE, Max. Principal (Avg: 75\%)
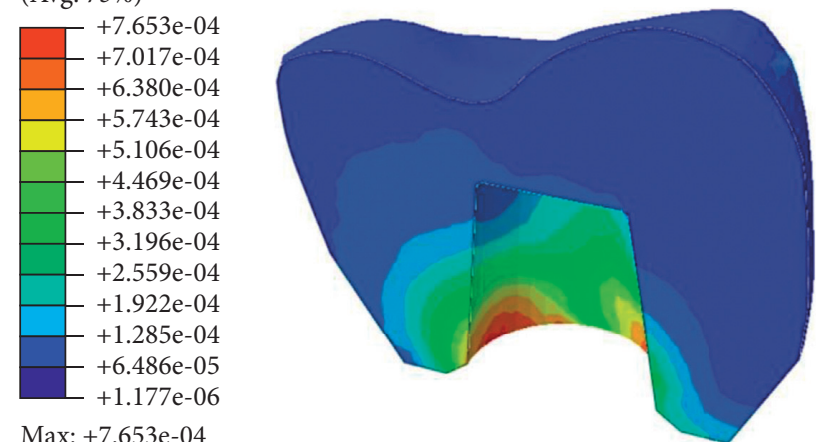

Max: +7.653e-04

Elem: IMPLANT-1-1.16494

Node: 542

Min: $+1.177 \mathrm{e}+06$

Elem: IMPLANT-1-1.310

Node: 3537 


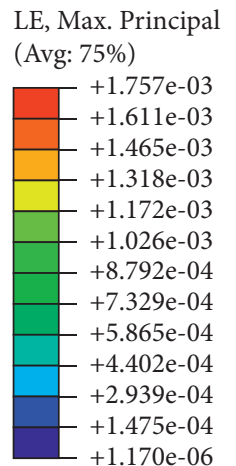

Max: $+1.757 \mathrm{e}-03$

Elem: IMPLANT-1-1.16494

Node: 542

Min: $+1.170 \mathrm{e}-06$

Elem: IMPLANT-1-1.7741

Node: 1527

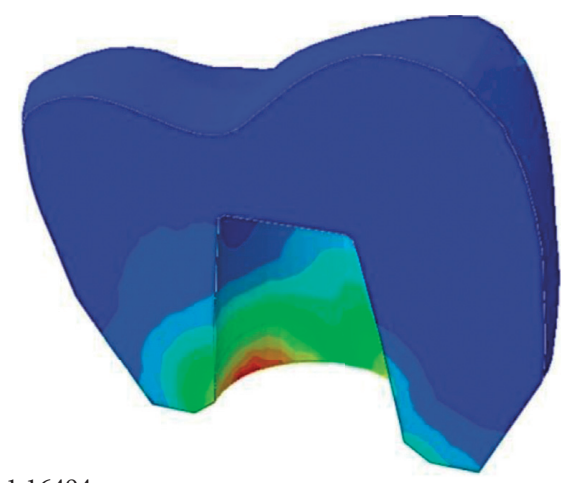

(c)

FIgURE 13: Strain distribution in the ceramic coating section for loads: (a) 2500, (b) 5000, and (c) $7500 \mathrm{~N}$.

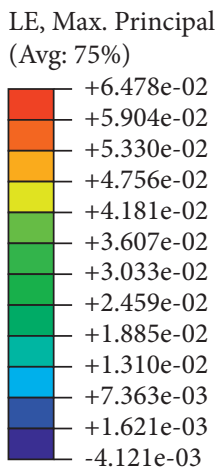

Max: $+6.478 \mathrm{e}-02$

Elem: IMPLANT-2-2.10576

Node: 488

Min: $-4.121 \mathrm{e}-03$

Elem: IMPLANT-2-2.19554

Node: 1328

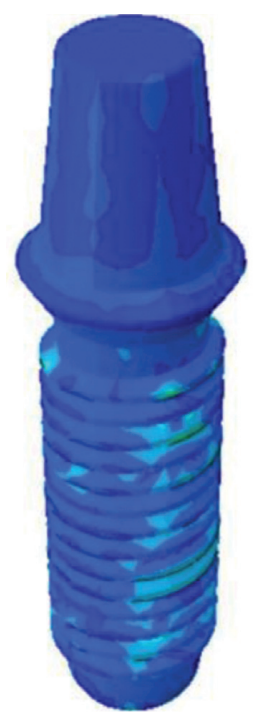

(a)

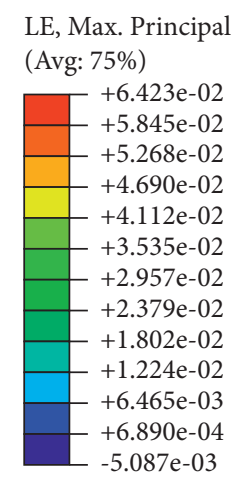

Max: +6.423e-02

Elem: IMPLANT-2-2.10576

Node: 488

Min: -5.087e-03

Elem: IMPLANT-2-2.24466

Node: 1567

(b)
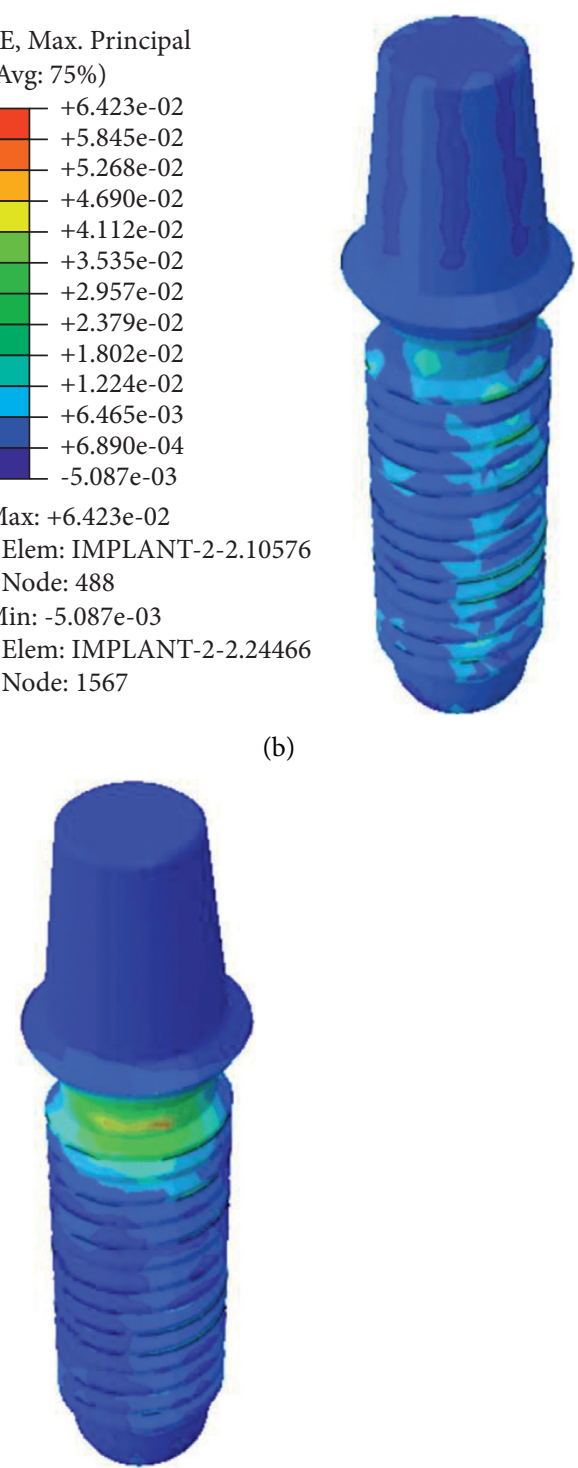

(c)

FIGURE 14: Strain distribution in the titanium implant section for loads: (a) 2500, (b) 5000, and (c) $7500 \mathrm{~N}$. 
LE, Max. Principal (Avg: $75 \%$ )

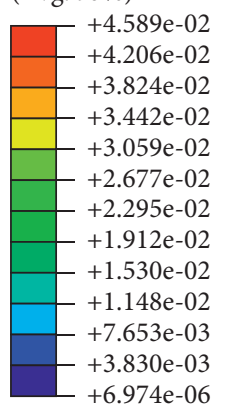

Max: +4.589e-02

Elem: MANDIBLE-1.31193

Node: 4189

Min: $+6.974 \mathrm{e}-06$

Elem: MANDIBLE-1.1971

Node: 8429

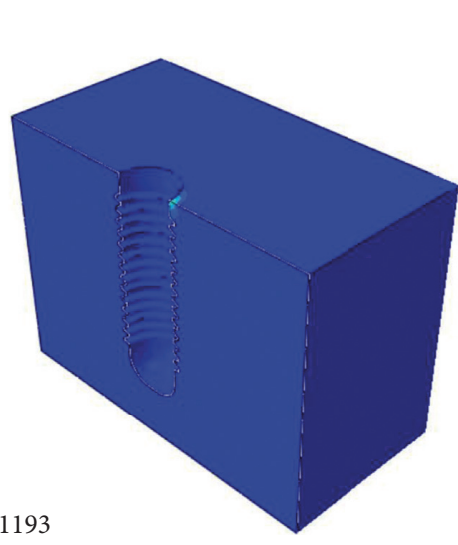

LE, Max. Principal (Avg: 75\%)

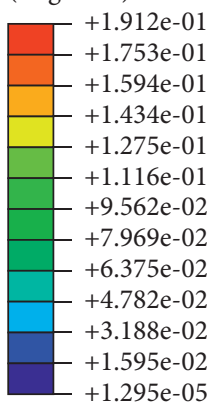

Max: $+1.912 \mathrm{e}-01$

Elem: MANDIBLE-1.31246

Node: 1993

Min: $+1.295 \mathrm{e}-05$

Elem: MANDIBLE-1.1971

Node: 8429

(a)

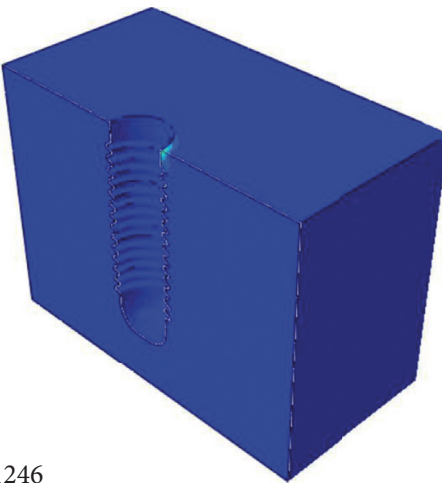

LE, Max. Principal (Avg: 75\%)

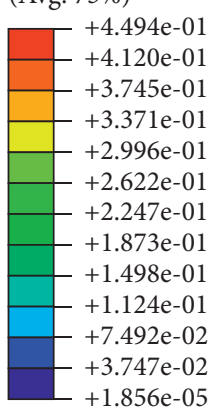

Max: $+4.494 \mathrm{e}-01$

Elem: MANDIBLE-1.31182

Node: 4194

Min: $+1.856 \mathrm{e}-05$

Elem: MANDIBLE-1.1971

Node: 8429

(c)

Figure 15: Strain distribution in the bone section for loads: (a) 2500, (b) 5000, and (c) $7500 \mathrm{~N}$.

U, Magnitude

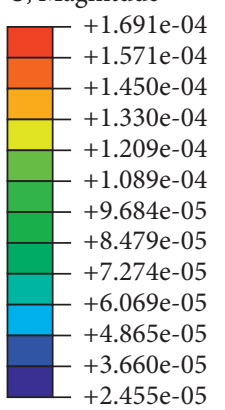

Max: $+1.691 \mathrm{e}-04$

Node: ASSEMBLY.1

Min: $+2.455 \mathrm{e}-05$

Node: IMPLANT-1-1.532
U, Magnitude
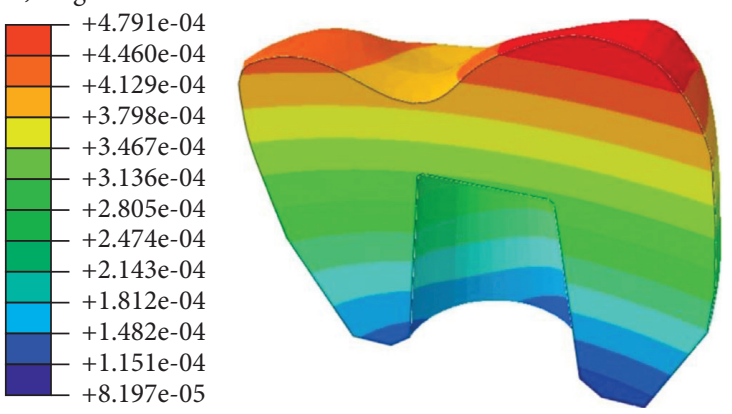

Max: +4.791e-04

Node: IMPLANT-1-1.184

Min: +8.197e-05

Node: IMPLANT-1-1.2089

(a)

Figure 16: Continued. 
U, Magnitude
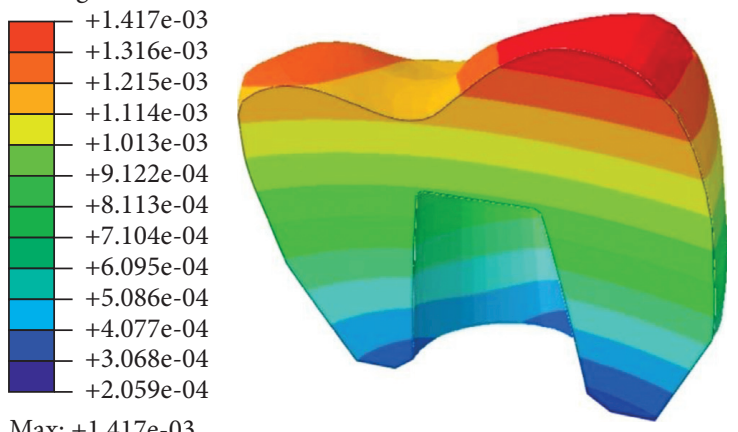

Max: +1.417e-03

Node: IMPLANT-1-1.184

Min: +2.059e-04

Node: IMPLANT-1-1.433

(c)

FIGURE 16: Deformation distribution in the ceramic coating section for loads: (a) 2500, (b) 5000, and (c) $7500 \mathrm{~N}$.

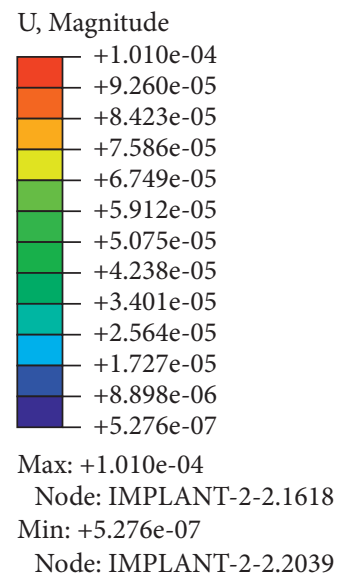

(a)
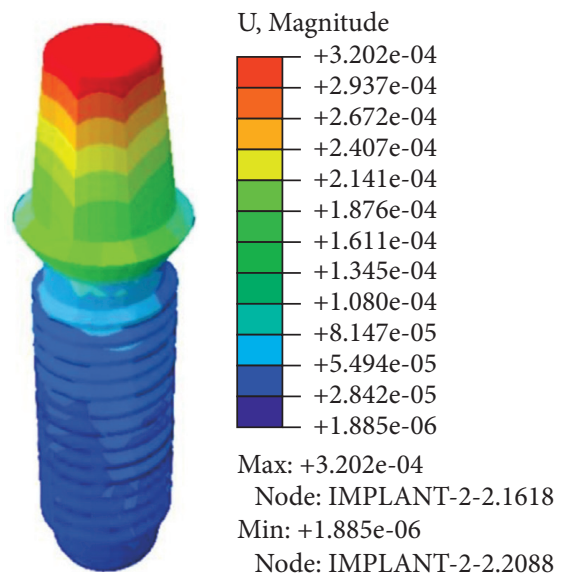

(b)

Node: IMPLANT-2-2.208
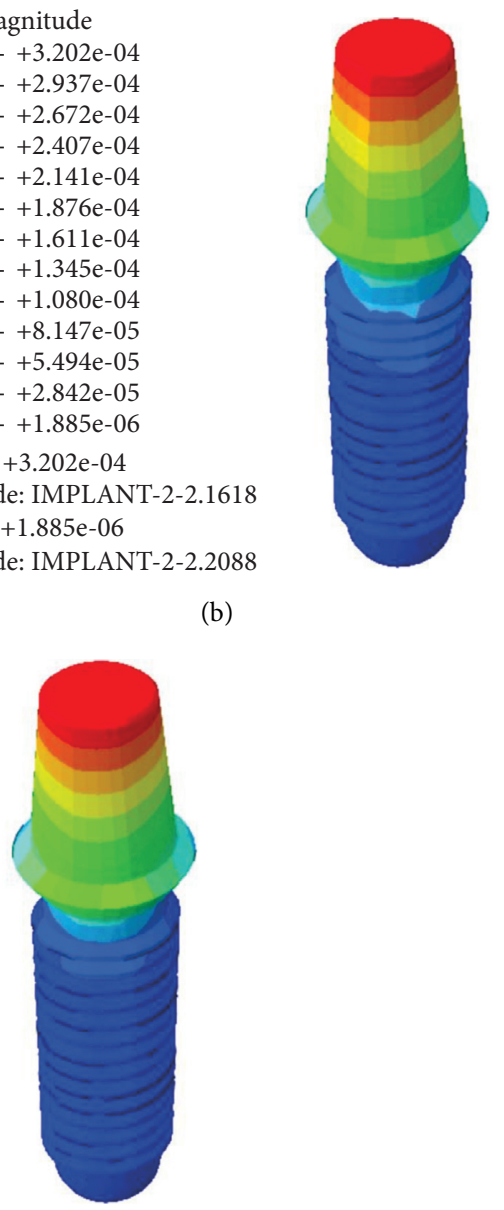

(c)

FIGURE 17: Distribution in the titanium implant section for loads: (a) 2500, (b) 5000, and (c) $7500 \mathrm{~N}$. 


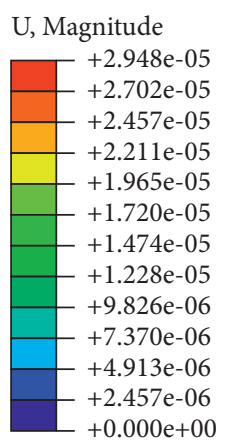

Max: $+2.948 \mathrm{e}-05$

Node: MANDIBLE-1.1995

Min: $+0.000 \mathrm{e}+00$ Node: MANDIBLE-1.246

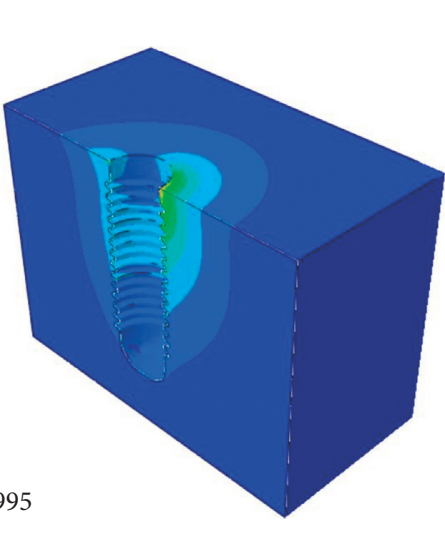

(a)
U, Magnitude

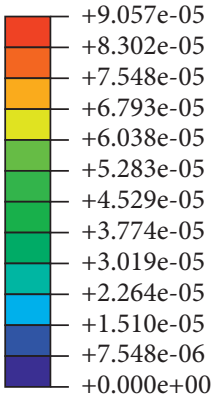

Max: +9.057e-05

Node: MANDIBLE-1.1995

Min: $+0.000 \mathrm{e}+00$

Node: MANDIBLE-1.246

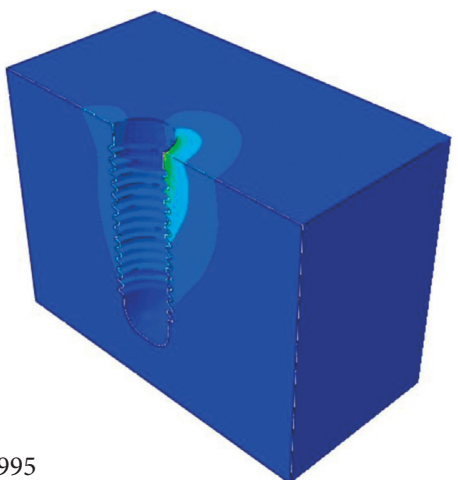

(b)

U, Magnitude
\begin{tabular}{|r|r}
\hline & $+2.528 \mathrm{e}-04$ \\
& $+2.317 \mathrm{e}-04$ \\
& $+2.107 \mathrm{e}-04$ \\
& $+1.896 \mathrm{e}-04$ \\
& $+1.685 \mathrm{e}-04$ \\
& $+1.475 \mathrm{e}-04$ \\
& +1.470 \\
& $+1.264 \mathrm{e}-04$ \\
& $+1.053 \mathrm{e}-04$ \\
& $+8.426 \mathrm{e}-05$ \\
\hline & $+6.320 \mathrm{e}-05$ \\
\hline & $+4.213 \mathrm{e}-05$ \\
& $+2.107 \mathrm{e}-05$ \\
& $+0.000 \mathrm{e}+00$
\end{tabular}

Max: $+2.528 \mathrm{e}-04$

Node: MANDIBLE-1.1996

Min: $+0.000 \mathrm{e}+00$

Node: MANDIBLE-1.246

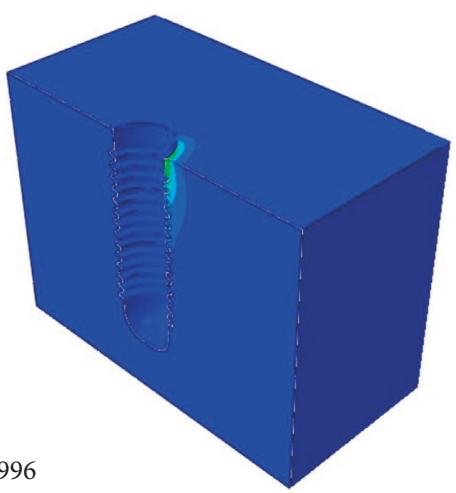

FIGURE 18: Bone deformation distribution for (a) 2500, (b) 5000, and (c) $7500 \mathrm{~N}$ loads.

TABLE 6: Temperature values in different parts of the model, due to the application of negative and positive heat flux.

\begin{tabular}{lcc}
\hline Model parts & Minimum temperature due to negative flux (Celsius) & Maximum temperature due to positive flux (Celsius) \\
\hline Ceramic coating & 23.48 & 48.5 \\
Titanium implants & 30.58 & 42.73 \\
Sponge bone & 34.65 & 39.3 \\
Cortical bone & 31.58 & 41.9 \\
\hline
\end{tabular}

TABle 7: Maximum stress values in different parts of the model due to negative and positive heat flux.

\begin{tabular}{lcc}
\hline Model parts & Maximum stress due to negative flux (MPa) & Maximum stress due to positive flux $(\mathrm{MPa})$ \\
\hline Ceramic coating & 2.355 & 2.420 \\
Titanium implants & 5.455 & 2.835 \\
Sponge bone & 0.03011 & 0.03208 \\
Cortical bone & 1.064 & 1.063 \\
\hline
\end{tabular}

3.6. Investigating the Effect of Heat Flux. Table 6 shows the temperature values in different parts of the model, due to the application of negative and positive heat flux.

Table 7 shows the maximum stress values caused by negative and positive heat flux in various regions of the model.

\section{Conclusion}

Over the years, dental implants have been researched as a way to replace missing teeth. One of the requirements for implant success is their stability and resistance to applied stresses, as well as minimum tension in the surrounding 
bone. The goal of this work is to use the finite element method to perform numerical and three-dimensional analysis of jaws with implants under mechanical and thermal loading. Implant simulations (containing ceramic crowns, titanium roots, and jawbone) under dynamic and thermal load were done in Abacus program for this purpose, and the following results were found after validation and assuring the reliability of modeling:
(1) The strains induced in all components of the ceramic covering, titanium implants, and jawbone have increased as the mechanical load has grown. It is worth noting that the stress levels shown are related to the von Mises result stress, which may be calculated using the equation below:

$$
\sigma^{*}=\frac{1}{\sqrt{2}}\left[(\sigma x x-\sigma y y)^{2}+(\sigma x x-\sigma \mathrm{zz})^{2}+(\sigma y y-\sigma \mathrm{zz})^{2}\right]^{0.5}
$$

(2) The highest levels of stress were seen in the titanium implant at varied loads, whereas the lowest quantities were observed in the jawbone due to the stress distribution.

(3) The strains caused in all regions of the ceramic covering, titanium implants, and jawbone have grown as the mechanical load has increased. It should be emphasized that the reported strain values are related to the elastic strain corresponding to the sum of all strain terms, as determined by the equation below:

$$
\varepsilon^{*}=\frac{1}{\sqrt{2(1+\nu)}}\left[(\varepsilon x x-\varepsilon y y)^{2}+(\varepsilon x x-\varepsilon z z)^{2}+(\varepsilon y y-\varepsilon z z)^{2}\right]^{0.5} .
$$

(4) It was discovered that, under different loads, the maximum values of strain occurred in the titanium implant and the lowest amount occurred in the ceramic covering due to the strain distribution.

(5) As the mechanical stress on the ceramic coating, titanium implants, and jawbone increases, deformations in all portions of the ceramic coating, titanium implants, and jawbone rise. It is worth noting that the values of the presented deformations are related to the result's deformation.

(6) The maximum amount of distortion occurred in the ceramic covering under varied weights, while the lowest amount occurred in the jawbone, owing to the deformation distribution.

(7) It has been noticed that, due to the effects of positive and negative heat flux, the temperature of the high surface of the ceramic coating that is exposed to the current has increased to $48.5^{\circ} \mathrm{C}$ when positive heat flux is applied and has reduced to $23.48^{\circ} \mathrm{C}$ when negative heat flux is applied. Furthermore, due to positive heat flow, the temperature of the titanium implant increased to $42.73^{\circ} \mathrm{C}$ and reduced to $30.58^{\circ} \mathrm{C}$ due to negative heat flux.

(8) When positive heat flux was applied to the jaw bone, the temperature of the spongy part of the bone rose to $39.30^{\circ} \mathrm{C}$, and when negative heat flux was applied, the temperature of the spongy part of the bone rose to $34.65^{\circ} \mathrm{C}$. Due to the positive heat flux, the temperature of the cortical section of the bone increased to $41.90^{\circ} \mathrm{C}$ and reduced to $31.58^{\circ} \mathrm{C}$.
(9) In thermal analysis of the implant and bone set, the maximum temperature transferred to the bone tissue through the implant is investigated. How much heat has reached the bone tissue and the contact surface of the implant with the bone? With some proteins denaturing at $42^{\circ} \mathrm{C}$ and above, as well as exposing the bone to $47^{\circ} \mathrm{C}$ for 1 minute, rising bone temperature can have fatal consequences. As a result of the findings of this study, it may be regulated that conditions of detrimental effects on bone tissue do not exist in patients with dental implants.

(10) When comparing the maximum stress values in different regions of the model, it was discovered that the stress caused by negative and positive heat flux in the ceramic covering, sponge bone, and cortical bone is about equivalent. While the stress induced in the titanium implant by negative heat flow was roughly twice that created by positive heat flux. This is due to the temperature gradient in the two circumstances being different. In the negative flux mode, the temperature gradient in the implant was around $7^{\circ}$, while in the positive flux mode, it was about $5^{\circ}$.

4.1. Suggestions. In this study, finite element analysis of the effect of dental implants on the jawbone under mechanical and thermal loading conditions and its results are presented. The following are suggestions for research in this area:

(1) Considering different contact models in modeling the placement of implants on the jawbone 
(2) Examining different types of implants with different geometry and materials and comparing their performance

(3) Optimizing the performance of dental implants according to various geometric and physical parameters

\section{Data Availability}

The data used to support the findings of this study are included within the article.

\section{Conflicts of Interest}

The authors declare that they have no conflicts of interest.

\section{References}

[1] C. Santiuste, M. Rodríguez-Millán, E. Giner, and H. Miguélez, "The influence of anisotropy in numerical modeling of orthogonal cutting of cortical bone," Composite Structures, vol. 116, pp. 423-431, 2014.

[2] T. Achour, A. Merdji, B. Bachir Bouiadjra, B. Serier, and N. Djebbar, "Stress distribution in dental implant with elastomeric stress barrier," Materials and Design, vol. 32, no. 1, pp. 282-290, 2011.

[3] A. Merdji, B. Bachir Bouiadjra, T. Achour, B. Serier, B. Ould Chikh, and Z. O. Feng, "Stress analysis in dental prosthesis," Computational Materials Science, vol. 49, no. 1, pp. 126-133, 2010.

[4] K. Oguz, E. Yuzbasiogu, and F. Erzincanh, "Static, dynamic and fatigue behaviors of dental implant using finite element method," Advances in Engineering Software, vol. 37, pp. 649-658, 2006.

[5] L. kong and Y. Zhao, K. Hu, D. Li, H. Zhou, Z. Wu, and B. Liu, Selection of the implant thread pitch for optimal biomechanical properties: a three-dimensional finite element analysis," Advances in Engineering Software, vol. 40, no. 7, pp. 474-478, 2009.

[6] N. Djebbae, B. Serier, B. Bachir Bouiadjra, S. Benbarek, and A. Drari, "Analysis of the effect of load direction on the stress distribution in dental implant," Materials and Design, vol. 31, 2009.

[7] K. Tian, J. Chen, L. Han, J. Yang, W. Huang, and D. Wu, "Angled abutments result in increased or decreased stress on surrounding bone of single-unit dental implants: a finite element analysis," Medical Engineering and Physics, vol. 34, no. 10, pp. 1526-1531, 2012.

[8] H.-L. Huang, J.-T. Hsu, L.-J. Fuh, D.-J. Lin, and M. Y. C. Chen, "Biomechanical simulation of various surface roughnesses and geometric designs on an immediately loaded dental implant," Computers in Biology and Medicine, vol. 40, no. 5, pp. 525-532, 2010.

[9] A. Dorogoy, D. Rittel, K. Shemtov-Yona, and R. Korabi, "Modeling dental implant insertion," Journal of the mechanical behavior of biomedical materials, vol. 68, pp. 42-50, 2017.

[10] H. Guan, R. C. van Staden, N. W. Johnson, and Y.-C. Loo, "Dynamic modelling and simulation of dental implant insertion process-a finite element study," Finite Elements in Analysis and Design, vol. 47, no. 8, pp. 886-897, 2011.
[11] M. Yazdi, "Ignorance-aware safety and reliability analysis: a heuristic approach," Quality and Reliability Engineering, vol. 36, 2019.

[12] M. Reza Khalili, B. Ziaie, and M. Kazemi, "Finite element analysis for dental implants subjected to thermal loads," Journal of Dental Medicine-Tehran University of Medical Sciences, vol. 26, no. 4, pp. 270-280, 2014.

[13] J. N. Reddy, An Introduction to the Finite Element Method, McGraw-Hill, New York, NY, USA, Third ed. edition, 2006.

[14] K. Wong, A. Boyde, and P. G. T. Howell, "A model of temperature transients in dental implants," Biomaterials, vol. 22, no. 20, pp. 2795-2797, 2001.

[15] L.-J. Fuh, J.-T. Hsu, H.-L. Huang, M. Y. Chen, and Y.-W. Shen, "Biomechanical investigation of thread designs and interface conditions of zirconia and titanium dental implants with bone: three-dimensional numeric analysis," The International Journal of Oral \& Maxillofacial Implants, vol. 28, no. 2, pp. e64-e71, 2013.

[16] P. Papaspyridakos, M. Mokti, C.-J. Chen, G. I. Benic, G. O. Gallucci, and V. Chronopoulos, "Implant and prosthodontic survival rates with implant fixed complete dental prostheses in the edentulous mandible after at least 5 years: a systematic review," Clinical Implant Dentistry and Related Research, vol. 16, no. 5, pp. 705-717, 2014.

[17] M. R. Niroomand and F. Jafari Maryaki, "Investigation on the effect of the contact model between dental implants and jaw bone on the maximum stress of implant using finite element method," Journal of Mechanics Enginnering, vol. 46, pp. 275-280, 2017.

[18] F.K. MohammadYazdi and R.R. RouzbehAbbassi, "Improved DEMATEL methodology for effective safety management decision-making," Safety Science, vol. 127, Article ID 104705, 2020.

[19] R. C. van Staden, H. Guan, N. W. Johnson, and Y.-C. Loo, "Performance evaluation of bone- implant system during implantation process: dynamic modelling and analysis," Springer Series in Biomaterials Science and Engineering, Springer, Berlin, Germany, pp. 45-69, 2017.

[20] T. Berglundh, L. Persson, and B. Klinge, "A systematic review of the incidence of biological and technical complications in implant dentistry reported in prospective longitudinal studies of at least 5 years," Journal of Clinical Periodontology, vol. 29, pp. 197-212, 2002.

[21] S. H. Chang, S. R. Huang, S. F. Huang, and C. L. Lin, "Mechanical response comparison in an implant overdenture retained by ball attachments on conventional regular and mini dental implants: a finite element analysis," Computer Methods in Biomechanics and Biomedical Engineering, vol. 19, pp. 911-21, Article ID 911921, 2016.

[22] V. Chappuis, R. Buser, U. Brägger, M. M. Bornstein, G. E. Salvi, and D. Buser, "Long-term outcomes of dental implants with a titanium plasma-sprayed surface: a 20 -year prospective case series study in partially edentulous patients," Clinical Implant Dentistry and Related Research, vol. 15, no. 6, pp. 780-790, 2013.

[23] Z. Zhang, J. Chen, E. Li, W. Li, M. Swain, and Q. Li, “Topological design of all-ceramic dental bridges for enhancing fracture resistance," International Journal for Numerical Methods in Biomedical Engineering, vol. 32, Article ID e02749, 2016.

[24] M. Yazdi, N. A. Golilarz, A. Nedjati, and K. A. Adesina, "An improved lasso regression model for evaluating the efficiency of intervention actions in a system reliability analysis," Neural Computing and Applications, vol. 33, 2021. 
[25] I. B. Babuska, O. Uday, and E. John, "Generalized finite element methods: main ideas, results, and perspective," International Journal of Computational Methods, vol. 1, no. 1, pp. 67-103, 2004.

[26] A. A. Solghar, A. Ali, and R. Mehrabi, "Simulation of mechanical behavior of dental implant made of shape memory alloy using the finite element method," Journal of Mashhad Dental School, vol. 43, no. 3, pp. 242-252, 2019.

[27] G. Molnár and A. Gravouil, " $2 \mathrm{D}$ and 3D Abaqus implementation of a robust staggered phase-field solution for modeling brittle fracture," Finite Elements in Analysis and DeSign, pp. 27-38, 2017.

[28] T. Nagasao, M. Kobayashi, Y. Tsuchiya, T. Kaneko, and T. Nakajima, "Finite element analysis of the stresses around fixtures in various reconstructed mandibular models-Part II (effect of horizontal load)," Journal of Cranio-Maxillofacial Surgery, vol. 31, no. 3, pp. 168-175, 2003.

[29] N. Prabhu, N. Naik, and V. Patil, "A study on effect of geometric patterns and material onstress distribution in dental implant system: a 3-dimensional finite element analysis", International Journal of Mechanical and Production, vol. 9, pp. 743-752, 2020.

[30] J. Ao, T. Li, Y. Liu et al., "Optimal design of thread height and width on an immediately loaded cylinder implant: a finite element analysis," Computers in Biology and Medicine, vol. 40, no. 8, pp. 681-686, 2010.

[31] P.-I. Brånemark, U. Breine, R. Adell, B. O. Hansson, J. Lindström, and $\AA$. Ohlsson, "Intra-osseous anchorage of dental prostheses:I. Experimental studies," Scandinavian Journal of Plastic and Reconstructive Surgery, vol. 3, no. 2, pp. 81-100, 1969. 